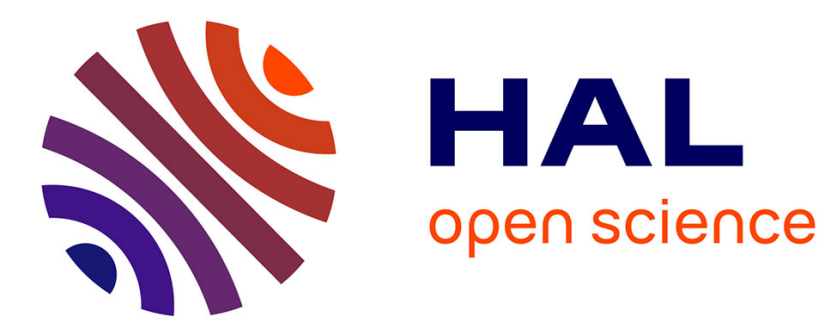

\title{
Experimentally valided approach for the simulation of the forging process using mechanical vibration
}

\author{
Rith Ly, Christophe Giraud-Audine, Gabriel Abba, Régis Bigot
}

\section{To cite this version:}

Rith Ly, Christophe Giraud-Audine, Gabriel Abba, Régis Bigot. Experimentally valided approach for the simulation of the forging process using mechanical vibration. International Journal of Material Forming, 2009, pp.133-136. 10.1007/s12289-009-0538-1 . hal-00781874

\section{HAL Id: hal-00781874 \\ https://hal.science/hal-00781874}

Submitted on 28 Jan 2013

HAL is a multi-disciplinary open access archive for the deposit and dissemination of scientific research documents, whether they are published or not. The documents may come from teaching and research institutions in France or abroad, or from public or private research centers.
L'archive ouverte pluridisciplinaire HAL, est destinée au dépôt et à la diffusion de documents scientifiques de niveau recherche, publiés ou non, émanant des établissements d'enseignement et de recherche français ou étrangers, des laboratoires publics ou privés. 


\title{
EXPERIMENTALLY VALIDED APPROACH FOR THE SIMULATION OF THE FORGING PROCESS USING MECHANICAL VIBRATION
}

\author{
LY Rith ${ }^{(1)^{*}}$, GIRAUD-AUDINE Christophe ${ }^{(2)}$, ABBA Gabriel ${ }^{(3)}$, BIGOT Régis ${ }^{(4)}$ \\ (1) University of Metz, LCFC, Ile du Saulcy, 57045 Metz Cedex 1, France \\ ${ }^{(2)}$ Arts et Métiers Paristech, LPMM, 4 rue Augustin Fresnel, 57078 Metz Cedex 03, France \\ ${ }^{(3)}$ Ecole Nationale d'Ingénieurs de Metz, LCFC, Ile du Saulcy, 57045 Metz Cedex 1, France \\ (4) Arts et Métiers Paristech, LCFC, 4 rue Augustin Fresnel, 57078 Metz Cedex 03, France
}

\begin{abstract}
In this study, an experimental setup of a forging process has been designed which allows to apply vibrations to the lower die of amplitude ranging from 0 to $80 \mu \mathrm{m}$ at frequencies varying from 1 to $130 \mathrm{~Hz}$ thanks to the use of a stack piezoelectric actuator fed by an electronic inverter. In order to explore those results, a coupling model has been developed to provide a design tool in a mechatronic frame which consists of an analytical model of the forging process based on simplified visco-plastic laws and a state space model of the piezoelectric actuator based on a finite element approach [1]. The coupling model can be used to analyse the important parameters of the whole process in order to optimize the forging process design using mechanical vibrations or to control the process if necessary. A finite element simulation of forging process using mechanical vibration based on finite element software Forge2008® is also presented in this study. The results obtained by experiment, finite element simulation and simulation using the model above are compared in the case of simple upsetting, with good agreement. Moreover, it can be concluded that high frequencies are not required to observe this phenomenon. Finally visco-plasticity phenomenon is not self-sufficient to explain completely the force reduction.
\end{abstract}

KEYWORDS: forming process design, ultrasonic vibration, piezoelectric actuator, mechatronic modelling.

\section{INTRODUCTION}

The use of vibrations in forming processes is known to provide beneficial effects such as reduction of the forming load, reduction of the flow stress, reduction of the surface friction between dies and workpiece and enhancement of the quality of the finished product $[2,3,4]$. These beneficial effects have been more studied in the scope of drawing processes but in the present work, we have specifically investigated the forging process (FP) by using plasticine as material model. More recently some authors investigated its use for forging operations. Most of the studies concluded positively that simulation results are difficult to compare with experiments because those models don't provide enough insight for practical guidance and for optimizing the use of the vibrations. That's why the design tool in a mechatronic frame was established in this paper.

Huang $[5,6]$ investigated FP using plasticine as material model of hot metal in forming processes and showed that the mean stress decreased appreciably with increasing the amplitude of vibrations but only a weak frequency dependency is observed. Hung [7] has experimentally presented the UV hot upsetting of the aluminium alloy and showed that the compressive force is reduced with increasing temperature or with influence of UV. Experimentally Siegert $[2,3]$ has investigated drawing force reduction and surface roughness in UV wire drawing and showed that the drawing force decreases with increasing amplitudes of UV and it is possible to reduce the friction by oscillating the die longitudinally with high frequency. Hayashi [8] has studied on finite element model (FEM) of UV wire drawing under the variation of the mode of oscillation and showed that using radial ultrasonic drawing get more drawing force reduction than using axial UV drawing. Mousavi [9] investigated UV in the extrusion process by means of the FEM and showed that the vibration frequency was less effective than vibration amplitude in reducing the extrusion force. Murakawa [4] has experimentally researched on UV wire drawing and showed that radial vibrations applied during drawing operation are more effective than the axial vibration.

The results reported above indicate that the mean forming load is affected by vibration depending on the amplitude and frequency of die vibration. To investigate this phenomenon, a model of the whole process has been developed including the actuator, the forging load and the power supply. Many researchers have investigated only piezoelectric modelling with an analytical approach $[10,11,12]$ or a finite element approach $[13,14,15]$ in flexible structure. However those models cannot be used simultaneously with FP. To overcome this problem, a FEM of piezoelectric actuator which can couple with an analytical model of FP was established. This coupling model were implemented using MATLAB ${ }^{\circledR}$. Moreover, an original experimental setup has been designed. The simulations obtained by the model above are compared with experimental results and finite element simulation based on Forge $2008^{\circledR}$.

\section{Experimental setup}

The experimental setup was build with a Lloyd test machine which is used to drive the upper die. A stack piezoelectric actuator (SPA) was chosen to vibrate the

\footnotetext{
* Corresponding author: 4 rue Augustin Fresnel, 57078 Metz Cedex 03, France, (33)618910561, lyrith@hotmail.com
} 
lower die. It is well suited to this application because of its high stiffness, high load capability and high power/weight ration in comparison with usual actuators. The piezoelectric actuator PSt 1000/16/60, manufactured by Piezomechanik $\mathrm{GmbH}$, was selected which provided the maximum load of $12 \mathrm{kN}$ and max amplitude of 80 $\mu \mathrm{m}$ for the maximum semi bipolar voltage $-200 \mathrm{~V} /+1000 \mathrm{~V}$. To prevent any mechanical damage, the SPA should only support forging load in longitudinal axis. Hence special mechanical setup had to be designed as shown in figure 1 . It can be equipped with 4 SPA (1) placed in parallel in an inner cylinder (2) and covered with flexible system which is elastically linked to the outer cylinder (3) by blades (4). It allows vibration only in the desired direction and prevents any torque to be transmitted to the SPA.

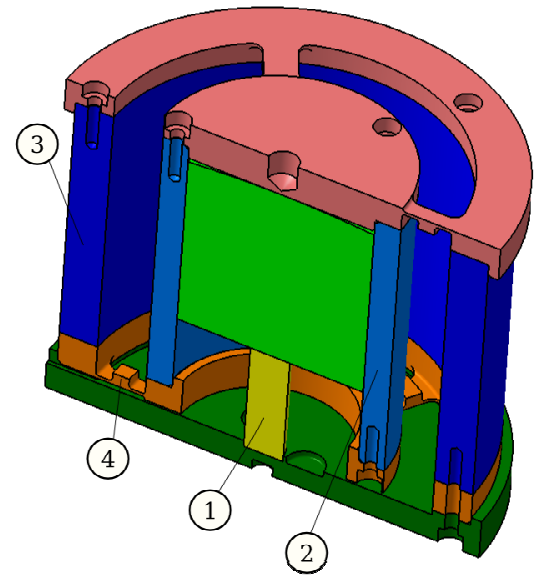

Figure 1: Mechanical setup view

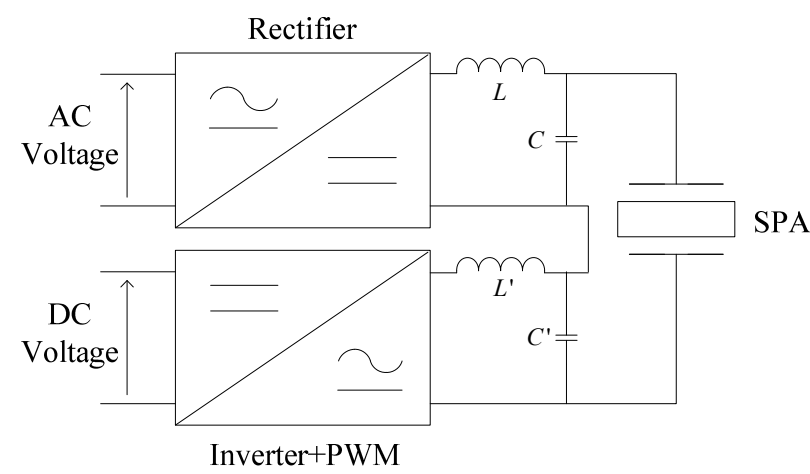

Figure 2: Electrical setup view

The electrical supply of the SPA (figure 2) is realised by connecting a rectifier, to produce a bias voltage, in series with output voltage of electronic inverter, which provides a variable voltage. Pulse Width Modulation (PWM) was used to control frequency, amplitude and voltage waveform. Moreover filters were employed to avoid any excitation of unwanted high frequency mechanical resonance by harmonic of the voltage. Voltage, current and vibration data of SPA are measured with differential probe, current probe and optical displacement sensors respectively. All data are measured through an acquisition card and treated with MATLAB ${ }^{\circledR}$.

\section{Modelling}

\subsection{Piezoelectric modelling}

The piezoelectric actuator has been modelled using a simplified mono-dimensional finite element approach and the linear equation of piezoelectricity. It provides a state space representation which had been implemented using MATLAB ${ }^{\circledR}[1]$. The electromechanical equations of the complete actuator are given by:

$$
\left\{\begin{array}{l}
\left(M+M_{\text {load }}\right) \ddot{U}(t)+K_{u} U(t)+K_{\phi u} \Phi(t)=F(t) \\
-K_{\phi u} U(t)+K_{\phi \phi} \Phi(t)=Q(t),
\end{array}\right.
$$

where $U(t)$ and $\Phi(t)$ are the matrix of structural displacements and electric potential respectively, $M$, $K_{u}, \quad K_{\phi u}$ and $K_{\phi \phi}$ are the mass, elastic, electromechanical and dielectric matrix respectively for the global system, $M_{\text {load }}$ is the mass matrix of the mechanical setup, $F(t)$ and $Q(t)$ are the force and electric charge imposed on piezoelectric actuator. In figure 3 , the above equations are implemented as a block where inputs are the voltage and the force, and the outputs are displacement, velocity of the die and the current. Moreover, inner deformation, constraints and electric charge can be calculated. It provides a tool to check that the SPA integrity is respected. Finally, damping can easily be introduced by the use of a proper damping matrix.

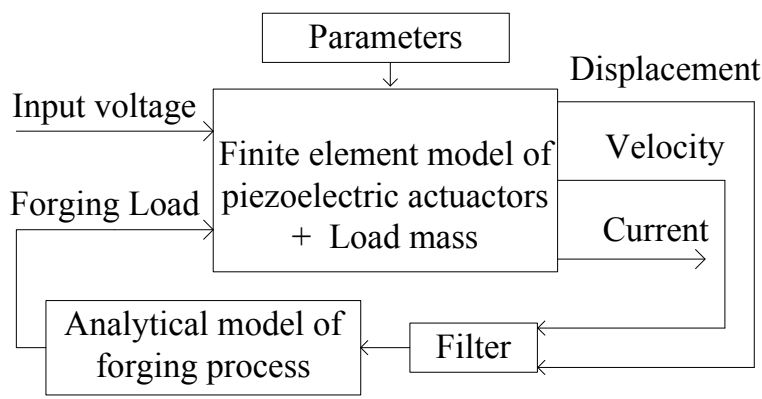

Figure 3: Schematic view of piezoelectric actuator with mechanical load

\subsection{Upsetting model}

\section{- Analytical model of the forging process}

Based on classical method, the goal is to predict forging load by taking into account the friction coefficient $\bar{m}$ between die and workpiece. Forging load is given by

$$
F=\frac{\pi D^{2}}{2 A} \sigma_{0}\left[\frac{1}{A}\left(e^{A}-1\right)-1\right]
$$

with $A=\frac{\bar{m} D}{h}$ and $\sigma_{0}=k \varepsilon^{n} \dot{\varepsilon}^{m}$

where $h, D$ are the height and diameter of cylindrical plasticine respectively, $k$ is material consistency, $n$ and $m$ are material constants, $\varepsilon=\left(h_{0}-h\right) / h$ is the 
equivalent strain, $\dot{\varepsilon}=-h_{0} \dot{h} / h^{2}$ is the strain speed, $h_{0}$ is the initial height. The variation of the speed of the height is given by $\dot{h}=v_{0}+\dot{u}_{3}(l, t)$ where $v_{0}$ is the upper die speed and $\dot{u}_{3}(l, t)$ is velocity outputs of FEM of piezoelectric actuator (lower die speed). The analytical model of FP is coupled with FEM of piezoelectric actuator and named coupling model as shown in figure 3 . This schematic bloc permits to analyse the use of vibration during the upsetting process. However this model of visco-plasticity phenomenon cannot explain completely the force reduction.

\section{- $\quad$ Finite element simulation of the forging process using mechanical vibration}

The FEM analysis of the FP using mechanical vibration was developed using the commercial finite element software FORGE2008 ${ }^{\circledR}$. The simulation conditions are set on the basis of the experimental condition (parameters can be found in Table 1). Rigid dies are piloted thanks to the curve representing the displacement in function of time. Time increment is equal to $0.0001 \mathrm{~s}$. In this paper, only the curves representing the load versus displacement are analyzed.

Table 1 shows the material properties and the upsetting conditions.

\begin{tabular}{ll}
\hline Material type & Plasticine \\
Die material & Steel \\
Sample size & $40 \mathrm{~mm} \times \varnothing 40 \mathrm{~mm}$ \\
Material consistency & $74000 \mathrm{~Pa}$ \\
Forging velocity & $3 \mathrm{~mm} / \mathrm{s}$ \\
Displacement reduction & $30 \mathrm{~mm}$ \\
Friction coefficient & 0.02 \\
Material constants $\mathrm{n}, \mathrm{m}$ & $0.154,0.16$ \\
\hline
\end{tabular}

\section{Preliminary results and discussion}

\subsection{Comparison of forging load without vibration}

Experimental results are employed to identify the parameters of cylindrical plasticine which are used for simulation as shown in table 1 . Figure 4 shows the forging load as a function of displacement for the FP obtained by experimental work, analytical model based on simplified visco-plastic laws and FEM based on FORGE2008 ${ }^{\circledR}$. It can be noted that the forging load increases with increasing the displacement and the curves obtained are in good agreement.

\subsection{Comparison of forging load with and without vibration}

The SPA can be supplied by the maximum semi bipolar voltage $-200 \mathrm{~V} /+1000 \mathrm{~V}$. To validate the model, the sinusoidal voltage with the amplitude $V_{P P}=300 \mathrm{~V}$ for the frequencies varying from 30 to $110 \mathrm{~Hz}$ was chosen to supply the SPA during the upsetting process. Figure 5 shows the comparison of measurements of the forging load as a function of the displacement with and without mechanical vibration (vibration curve are filtered). The curves show one of those measurements $(110 \mathrm{~Hz})$. The lower die speed $6.2 \mathrm{~mm} . \mathrm{s}^{-1}$ is estimated by knowing the voltage supplied. The upper die is driven by Lloyd test machine with the speed $v_{0}=1 \mathrm{~mm} \cdot \mathrm{s}^{-1}$. It can be noted that a substantial reduction of the mean forging load can be obtained by the application of mechanical vibration to the lower die.

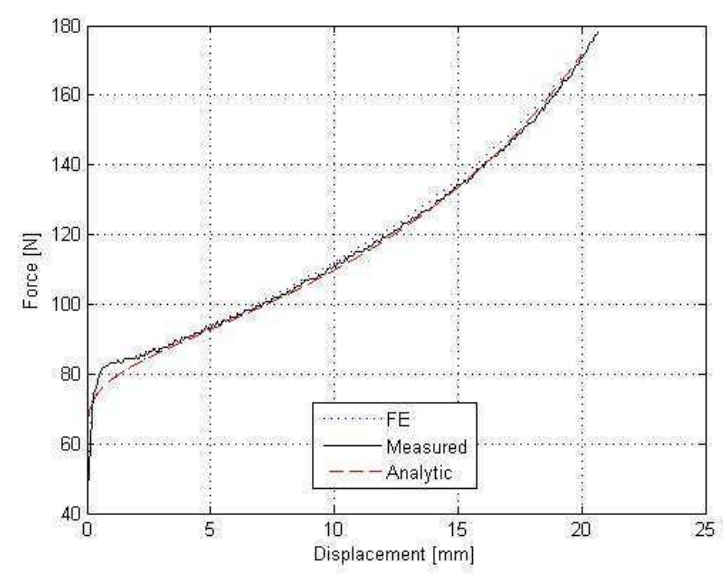

Figure 4: Variation of forging load versus displacement without mechanical vibration

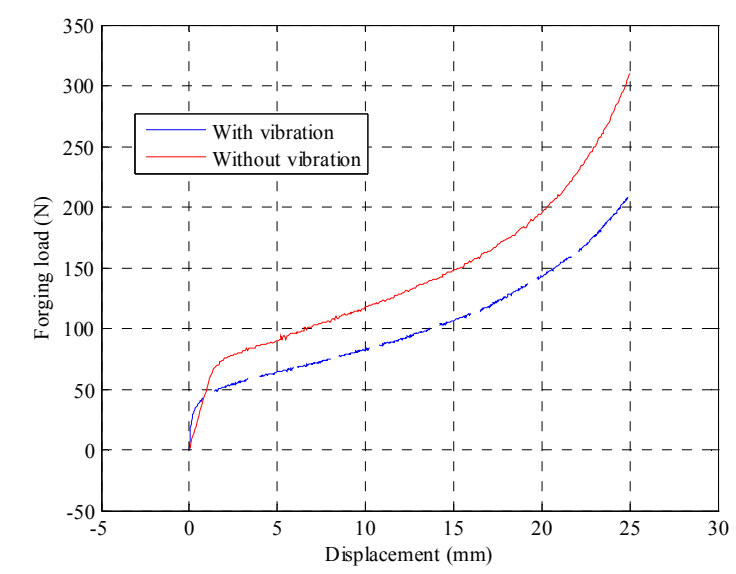

Figure 5: Variation of forging load versus displacement with and without mechanical vibration

\subsection{Comparison of forging load ratio}

One can quantify the effect of vibration on the forging load reduction by taking the ratio of the forging loads for a given vibration and without vibration. For the experiment, the coupling model (analytic) and the FEM of FP, the SPA was supplied with the sinusoidal voltage as mentioned above. The results are summed up in Fig 6 where the forging load reduction is plotted against the normalised speed, defined as the ratio between the vibration speed and the upper die speed. The reduction varies monotonically in every case so a correlation between those variables seems to be confirmed. However many uncertainties remain. On the experimental side, the speed of the vibration (lower die 
speed) is only estimated by knowing the voltage applied and the piezoelectric constant, moreover the bandwidth of the force measurement is low, so higher order effects can not be measured. This could explain such discrepancies between the measurement and the FEM. Regarding the latter, many problems still have to be solved to multiply the simulations which are so far very lengthy and difficult to treat due to the large number of points needed. Finally the coupling model, although very simple, predicts correctly the experimental measurements, but its validity domain should be extended using more complete rheological model to account for the elastic domain.

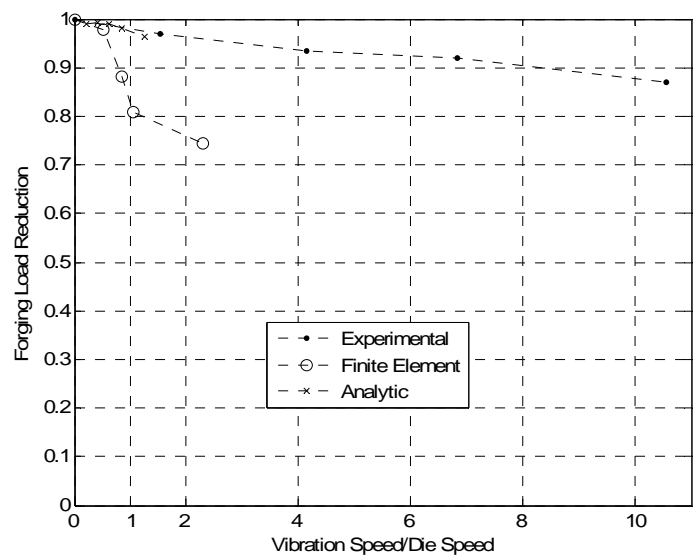

Figure 6: Comparisons of the forging load reduction vs normalised speed

\section{CONCLUSIONS}

In this paper, a complete experiment of upsetting using mechanical vibration has been developed. It has been modelled and implemented using MATLAB ${ }^{\circledR}$ and allows a complete mechatronic simulation which can be used to analyse the vibration during FP. It seems to predict correctly the experimental results. Simultaneously, a FE simulation study was undertaken in order to investigate the factors that may explain the forging load reduction. Every approach seems to indicate that the ratio between the vibration speed and the upper die speed is an important factor. Experiments and FEM also confirmed that the reduction of the forging load can not solely be explained by the visco-plastic behaviour and that elastic unloading also occurs. However, many actions must be undertaken to improve the models and the measurements. Especially, the electrical energy consumption should be compared with the forging energy gains to validate an improvement in the energy balance. To this respect, low frequencies are desirable to avoid large reactive currents in the piezoelectric.

\section{ACKNOWLEDGEMENT}

The authors would like to thank the "Fédération GI2M" of Metz and the French Ministry of High Education and Research for their financial support and Mr Morhain for his technical support during experimental tests.

\section{REFERENCES}

[1] Ly R., C. Giraud-Audine, R. Bigot, G. Abba, Longitudinal vibration modeling of a piezoelectric actuator used in forming process, IEEE international conference on Mechatronics, Malaga, Spain, 14-17 April, 2009, accepted.

[2] Siegert K., A. Mock, Wire drawing with ultrasonically oscillating dies, Journal of Materials Process. Technol., 60:657-660, 1996.

[3] Siegert K., J. Ulmer, Superimposing ultrasonic waves on the dies in tube and wire drawing, J. Eng. Mater. Technol. 123: 517-523, 2001.

[4] Murakawa M., M. Jin, The utility of radially and ultrasonically vibrated dies in the wire drawing process, J. Mater. Process. Technol. 113: 81-86, 2001.

[5] Huang Z., M. Lucas, MJ. Adams, Modelling wall boundary conditions in an elasto-viscoplastic material forming process, Journal of Materials Process. Technol., 107:267-75, 2000.

[6] Huang Z., M. Lucas, MJ. Adams, Influence of ultrasonics on upsetting of a model paste, Ultrasonics, 40:43-48, 2002.

[7] Hung J.C., C. Hung, The influence of ultrasonicvibration on hot upsetting of aluminium alloy, Ultrasonics, 43:692-698, 2005.

[8] Hayashi M., M. Jin, S. Thipprakmas, M. Murakawa, J.C. Hung, Y.C. Tsai, C.H. Hung, Simulation of ultrasonic-vibration drawing using the finite element method, Journal of Materials Process. Technol., 140:30-35, 2003.

[9] Mousavi S.A., H. Feizi, R. Madoliat, Investigations on the effects of ultrasonic vibrations in the extrusion process, Journal of Materials Process. Technol., 187-188 (2007) 657-661.

[10] Giraud-Audine C., B. Nogarède, Analytical modelling of travelling wave piezomotor stators using a variational approach, Eur. Phys. J. AP, 6:69-79, June 1997.

[11] Goldfarb M., N. Celanovic, Modelling piezoelectric stack actuators for control of micromanipulation, IEEE Contr. Syst. Mag., 17:69-79, 1997.

[12] Adriaens H.J.M.T.A., W. L. de Koning, R. Banning, Modeling piezoelectric actuators. IEEE/ASME Trans. Mechatronics, 5:331, 2000.

[13] Piefort V., A. Preumont, Modeling of smart piezoelectric shell structures with finite elements, $25^{\text {th }}$ International Conference on Noise and Vibration Engineering, ISMA25, Leuven, Belgium.

[14] Tliba S., H. Abou-Kandil, C. Prieur, Active vibration damping of smart flexible structure using piezoelectric transducesr: H-infinity design and experimental results, In proceedings of the 16th IFAC Wold Congress, vol. 16. Prague, Czech Republic, July 4-8, 2005.

[15] Wang Z., S. Chen, W. Han, Static shape control for intelligent structures, Finite Elements Anal. Des, 26:303-314, 1997. 